\title{
Transformations in the Fluorescence Line Narrowing Spectra of Porphine upon the Formation of Diprotonated Species
}

\author{
Alexander S. Starukhin, ${ }^{\mathrm{a} @ ~ M i k a l a i ~ M . ~ K r u k, ~}{ }^{a} \mathrm{Ol}^{\prime}$ ga L. Gladkova, ${ }^{\mathrm{b}}$ and Wouter Maes ${ }^{\mathrm{c}, \mathrm{d}}$ \\ ${ }^{a}$ B.I. Stepanov Institute of Physics of National Academy of Sciences, 220072 Minsk, Republic of Belarus \\ ${ }^{\mathrm{b} B e l a r u s i a n}$ State University of Informatics and Radioelectronics, 220013 Minsk, Republic of Belarus \\ 'Institute for Materials Research (IMO), Research Group Organic and (Bio)Polymer Chemistry, Hasselt University, B-3590 \\ Diepenbeek, Belgium \\ ${ }^{\mathrm{d}}$ Molecular Design and Synthesis, Department of Chemistry, Katholieke Universiteit Leuven, B-3001 Leuven, Belgium \\ ${ }^{\circledR}$ Corresponding authorE-mail:astar@imaph.bas-net.by
}

\begin{abstract}
Fluorescence line narrowing spectra of the diprotonated forms of the porphine have been obtained in solid acid solutions at liquid helium temperature. Quantum-chemical calculations of frequencies and forms of in-plane and out-of-plane vibrations for the diprotonated forms were also performed. The manifestation of intense vibronic transitions in the fineline fluorescence spectra of diprotonated forms of $\mathrm{H}_{2} \mathrm{P}$ with participation of out-of-plane modes have been estimated on the basis of mutual analysis of the experimental data and the results of quantum chemical calculations. The reason for the spectral activation of out-of-plane modes consists in saddle distortion of the porphine molecule upon formation of the diprotonated form.
\end{abstract}

Keywords: Porphine, fluorescence line narrowing spectra, diprotonated form, saddle conformation.

\section{Introduction}

The high importance of tetrapyrrolic compounds for current science and technology has led to intensive studies of these compounds by different spectral methods. It is well known that vibronic spectra of porphyrins in solid solutions have been unresolved even at liquid helium temperature. Upon narrow band laser excitation in the range of the $\mathrm{S}_{0} \rightarrow \mathrm{S}_{1}$ absorption spectrum at liquid helium temperatures, the inhomogeneous broadening in fluorescence spectra is removed. This method was named the fluorescence line narrowing (FLN) procedure ${ }^{[1]}$ and was used successfully for the study of tetrapyrrolic compounds in the different kinds of solid amorphous glasses. It is of particular interest to apply FLN method for the detection of fine-line fluorescence spectra for the protonated forms of porphyrins in acid solid solutions.

Free base porphyrins when reacted with acids are transformed. The spectral data for the diprotonated forms of octaethylporphyrin were detected in unresolved fluorescence spectra at $77 \mathrm{~K}^{[2]}$ Later, the occurrence of the monodeprotonated form of octaethylporphyrin has been detected in fluorescence and absorption spectra, ${ }^{[3]}$ also. The structure of the diprotonated forms of porphyrins has been studied on the basis of the X-ray data, ${ }^{[4,5]}$ where saddle type of distortion of these forms was estimated.

At low temperatures only the diprotonated forms of tetrapyrrolic compounds are realized. First, the FLN spectra of free base porphine $\left(\mathrm{H}_{2} \mathrm{P}\right)$ in solid solution of trifluoroacetic acid matrix at $4.2 \mathrm{~K}$ were detected ${ }^{[6]}$ but the data have not interpreted. Several years ago the fine-line spectrum of diprotonated form of $\mathrm{H}_{2} \mathrm{P}$ in inorganic tetraethoxysilane matrix at $4.2 \mathrm{~K}$ was detected, ${ }^{[7]}$ but these results have essential differences if compared with the previous data ${ }^{[6]}$ and the interpretation of the spectral data is also absent. Later single site fluorescence and absorption spectra of free base octaethylporphyrin, octaethylchlorin and their respective diacids in $n$-octane were reported also at $298 \mathrm{~K}$ and $7 \mathrm{~K}{ }^{[8]}$

In this work, we have measured high-resolution FLN spectra of the diprotonated forms of $\mathrm{H}_{2} \mathrm{P}$. We have performed quantum-chemical calculations of the frequencies and forms of in-plane and out-of-plane vibrations of these compounds. Based on the experimental data and calculation results the manifestation of out-of-plane vibrations in the vibronic fluorescence spectra of diprotonated forms of $\mathrm{H}_{2} \mathrm{P}$ have been analyzed and the relationship between the activity of out-ofplane modes and their forms, was estimated.

\section{Experimental}

The $\mathrm{H}_{2} \mathrm{P}$ was synthesized according to the well known method. ${ }^{[9]}$ For purification and identification of the structure standard procedures have been used.

Diprotonated species were prepared under dissolving of the $\mathrm{H}_{2} \mathrm{P}$ in mixture of acetonitrile $/ 10^{-3} \mathrm{M} \mathrm{HClO}_{4}\left(\mathrm{H}_{4} \mathrm{P}^{2+}\right)$ and in mixture of acetonitrile $/ 10^{-3} \mathrm{MD}_{2} \mathrm{SO}_{4}\left(\mathrm{D}_{4} \mathrm{P}^{2+}\right)$. The $\mathrm{D}_{4} \mathrm{P}^{2+}$ is chemically similar to $\mathrm{H}_{4} \mathrm{P}^{2+}$ form but the central hydrogen atoms were exchanged on the deuterium atoms. The structural formulae of the $\mathrm{H}_{2} \mathrm{P}, \mathrm{H}_{4} \mathrm{P}^{2+}$ and the $\mathrm{D}_{4} \mathrm{P}^{2+}$ are shown in Figure 1 .

Dilute solutions of the porphyrins in acetonitrile-acids mixtures (Fluka, spectroscopic grade) were cooled in liquid helium $(4.2 \mathrm{~K})$. To minimize the concentration and aggregation effects the samples of the diprotonated forms of porphine with concentrations $\sim 10^{-6} \mathrm{M}$ have been used.

Upon applying the FLN procedure the inhomogeneous spectral broadening is removed and the fluorescence spectra are transformed from broad bands in a set of narrow zero-phonon lines. ${ }^{[1]}$ The difference in frequencies between lines of fluorescence and the 


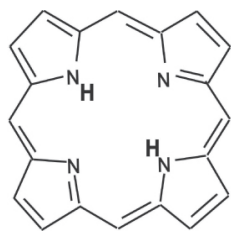

a

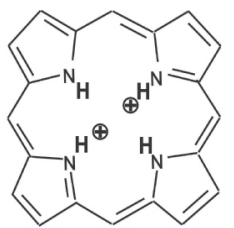

b

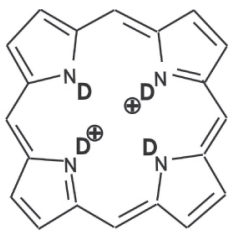

c
Figure 1. The structure of the $\mathrm{H}_{2} \mathrm{P}(\mathrm{a}), \mathrm{H}_{4} \mathrm{P}^{2+}(\mathrm{b})$ and $\mathrm{D}_{4} \mathrm{P}^{2+}$ (c).

excitation laser line is equal to the frequency of the corresponding vibration in the ground state ${ }^{[1]}$. For molecules with relatively high symmetry the same set of vibrations will be manifested in FLN spectra as well as in the resonance Raman spectra (RRS).

The luminescence spectra of the compounds of interest have been recorded using a highly sensitive home-build spectrometer based on double monochromator of DFS-24 spectrometer. The samples were excited by radiation from a pulsed dye laser (wavelength range is $550-700 \mathrm{~nm}$, line width less than $0,1 \mathrm{~nm}$ ). It was pumped by the second harmonic of Nd-YAG laser (wavelength is $532 \mathrm{~nm}$, pulse width $\sim 12 \mathrm{~ns}$, repetition rate $20 \mathrm{~Hz}$ ). The luminescent signals were detected with a photomultiplier tube (Hamamatsu, type R-928) and a two-channel boxcar integrator RIS-2002. More detailed the experimental setup was described elsewhere. ${ }^{[9]}$

\section{Quantum-Chemical Calculations of Vibrational States}

Quantum-chemical calculations of the frequencies and symmetry of the normal modes as well as the maximum amplitude change for natural coordinates have been done by a DFT method using the exchange-correlative functional BPE and software package "Priroda" ${ }^{[10]}$ The quantum-chemical calculations for the equilibrium configuration of isolated molecules of the $\mathrm{H}_{4} \mathrm{P}^{2+}$ and $\mathrm{D}_{4} \mathrm{P}^{2+}$ were carried out. The calculated frequencies were not scaled.
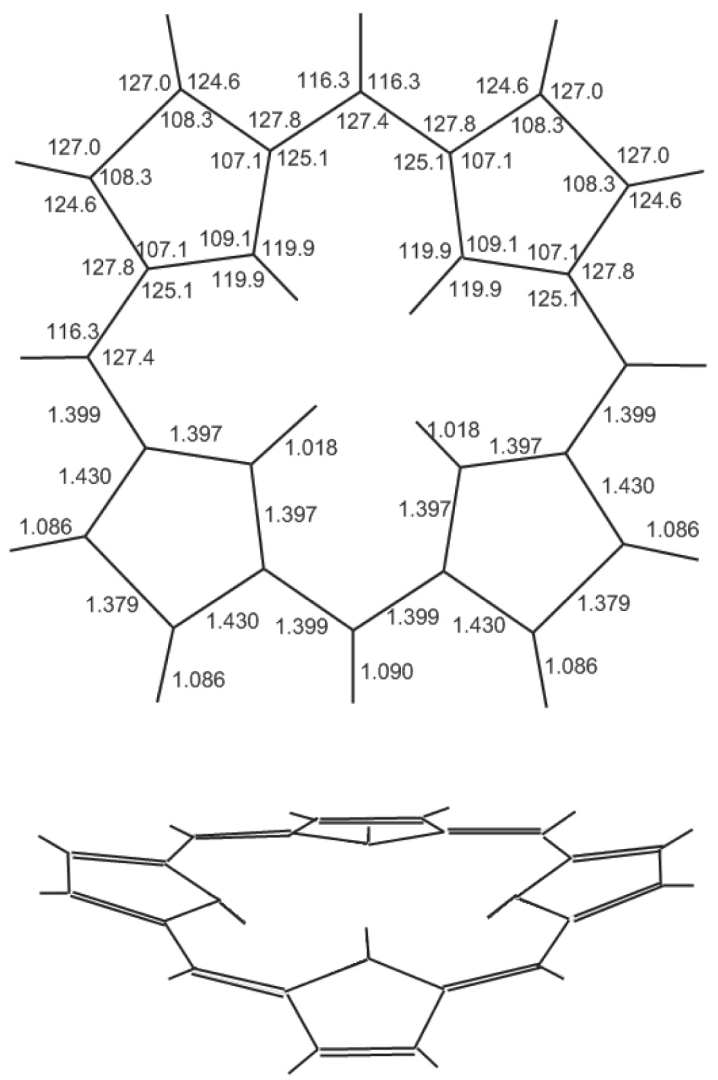

Figure 2. Optimized structure of $\mathrm{H}_{4} \mathrm{P}^{2+}$.
The optimization of $\mathrm{H}_{4} \mathrm{P}^{2+}$ geometry for shows that this compound has an out-of-plane structure ( $D_{2 \mathrm{~d}}$ symmetry group) in contrary to the $\mathrm{H}_{2} \mathrm{Pmolecule}$ with a planar structure. In the optimized structure of $\mathrm{H}_{4} \mathrm{P}^{2+}$ (see Figure 2), the two of opposite protons turn relatively to the $\mathrm{CC}$-bonds of the methine bridges so that its nitrogen atoms are spaced above the plane of methine bridges, and the two remaining protons are under the plane. It is a typical saddle form of a porphyrin macrocycle. This structure of $\mathrm{H}_{4} \mathrm{P}^{2+}$ corresponds very well to the X-ray data for diprotonated forms of porphyrins. ${ }^{[4,5]}$ The tilting dihedral $\mathrm{C}_{b} \mathrm{C}_{\mathrm{a}} \mathrm{C}_{\mathrm{m}} \mathrm{C}_{\mathrm{a}}$ and $\mathrm{C}_{\mathrm{a}} \mathrm{C}_{\mathrm{m}} \mathrm{C}_{\mathrm{a}} \mathrm{N}$ angles have a value of $9^{\circ}$. Under these conditions the corresponding $\mathrm{NH}$ band has a tilt above and under the plane of the pyrrolic rings (dihedral $\mathrm{C}_{\mathrm{b}} \mathrm{C}_{\mathrm{a}} \mathrm{NH}$ angle is equal to $32^{\circ}$ ).

\section{Results and Discussion}

Highly resolved FLN spectra of $\mathrm{H}_{2} \mathrm{P}$, the $\mathrm{H}_{4} \mathrm{P}^{2+}$ and $\mathrm{D}_{4} \mathrm{P}^{2+}$ have been detected in solid solution. Figure 3 shows the fine-structure fluorescence spectra of aforementioned compounds upon selective laser excitation at $4.2 \mathrm{~K}$. The data on the frequencies of the vibronic lines in the FLN spectra of $\mathrm{H}_{4} \mathrm{P}^{2+}$ and $\mathrm{D}_{4} \mathrm{P}^{2+}$ are summarized in Table 1 . The frequencies and symmetry of the normal modes have been established on the basis of quantum-chemical calculations for $\mathrm{H}_{4} \mathrm{P}^{2+}$ and $\mathrm{D}_{4} \mathrm{P}^{2+}$ and are presented in the Table 1, also.

The molecule of $\mathrm{H}_{4} \mathrm{P}^{2+}$ belongs to the $D_{2 \mathrm{~d}}$ symmetry group and $\mathrm{H}_{2} \mathrm{P}$ - to the $D_{2 \mathrm{~h}}$ symmetry group. The symmetrical metalloporphine with position of the metal atom in the plane of macrocycle belongs to the $D_{4 \mathrm{~h}}$ symmetry group. As a result of the existing axes of fourth order for the $D_{2 \mathrm{~d}}$ and $D_{4 \mathrm{~h}}$ there is a possibility to compare vibrational types of symmetry for these groups. In total, the symmetric modes of $A_{1}\left(D_{2 \mathrm{~d}}\right)$ correspond to the in-plane $A_{1 \mathrm{~g}}$ vibrations and out-of-plane $B_{2 \mathrm{u}}$ modes; $B_{1}$ modes $\left(D_{2 \mathrm{~d}}\right)-B_{2 \mathrm{~g}}$ and $A_{1 \mathrm{u}}\left(D_{4 \mathrm{~h}}\right) ; B_{2}\left(D_{2 \mathrm{~d}}\right)-B_{1 \mathrm{~g}}$ and $A_{2 \mathrm{u}}\left(D_{4 \mathrm{~h}}\right) ; A_{2}\left(D_{2 \mathrm{~d}}\right)-A_{2 \mathrm{~g}}$ and $B_{1 \mathrm{u}}\left(D_{4 \mathrm{~h}}\right) ; E \operatorname{modes}\left(D_{2 \mathrm{~d}}\right)-$ with $E_{\mathrm{u}}$ and $E_{\mathrm{g}}\left(D_{4 \mathrm{~h}}\right)$ types of symmetry.

Combined discussion of the experimental data and the results of quantum-chemical calculations of the normal modes for our compounds starts from the comparison of the data for $\mathrm{H}_{2} \mathrm{P}$ and $\mathrm{H}_{4} \mathrm{P}^{2+}$. The frequencies of many modes in the FLN spectrum of $\mathrm{H}_{4} \mathrm{P}^{2+}$, in particular, in the range up to $1000 \mathrm{~cm}^{-1}$, have values similar to that in the spectrum of $\mathrm{H}_{2} \mathrm{P}$. In the cases where one line may be compared with several calculated modes we keep the assignments for the corresponding interpretation of $\mathrm{H}_{2} \mathrm{P}$.

The lines about $1600 \mathrm{~cm}^{-1}$ in the FLN spectra of $\mathrm{H}_{4} \mathrm{P}^{2+}$ belong to the modes with participation of the $\mathrm{C}_{\mathrm{a}} \mathrm{C}_{\mathrm{m}}$ bonds. In contrast to the situation in the spectrum of $\mathrm{H}_{2} \mathrm{P}$ these vibrations are sensitive to deuterated atoms at central positions of $\mathrm{H}_{4} \mathrm{P}^{2+}$ (see Table 1). The changing value of the line with frequency $1618 \mathrm{~cm}^{-1}$ upon deuteration arises from the motion of nitrogen atoms, because the deformation shift of $\mathrm{C}_{\mathrm{a}} \mathrm{C}_{\mathrm{m}}$ atoms for $B_{2}$ mode is forbidden in symmetry. As a result the nitrogen atoms will shift hydrogen atoms along axes passing through the nitrogen atoms of opposite pyrrole rings. Calculated modes are not shifted upon deuteration and it means that the contribution of nitrogen atom will be more than the theoretical calculation predicts.

Similarly, the lines with frequencies $310,723,953$, 1182,1318 and $1388 \mathrm{~cm}^{-1}$ in the spectrum of $\mathrm{H}_{2} \mathrm{P}$ do not change their values upon deuteration of the center of $\mathrm{H}_{2} \mathrm{P}$ $\left(\mathrm{D}_{2} \mathrm{P}\right)$. At the same time upon deuteration the corresponding lines of $\mathrm{H}_{4} \mathrm{P}^{2+}$ are shifted on several $\mathrm{cm}^{-1}$. 


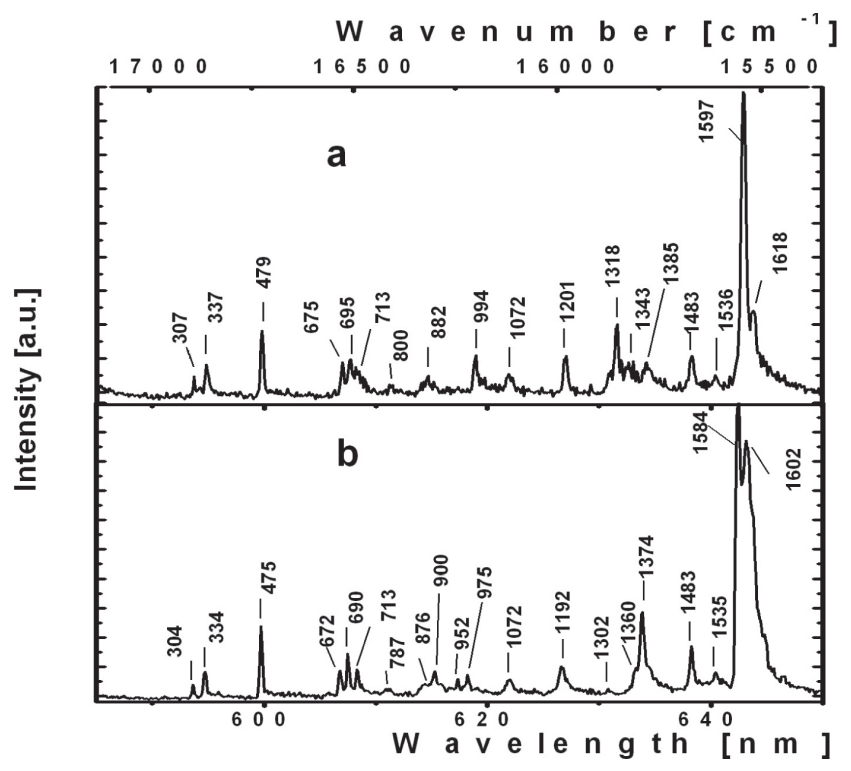

Figure 3. FLN spectra of $\mathrm{H}_{4} \mathrm{P}^{2+}$ in the mixture of acetonitryle/10${ }^{3} \mathrm{M} \mathrm{HClO}_{4}$ (a) and $\mathrm{D}_{4} \mathrm{P}^{2+}$ in the mixture of acetonitryle $/ 10^{-3} \mathrm{M}$ $\mathrm{D}_{2} \mathrm{SO}_{4}\left(\right.$ b) upon selective excitation $\left(\lambda_{\text {exc }}=585 \mathrm{~nm}\right)$ at $4.2 \mathrm{~K}$.

Deuteration of the center of $\mathrm{H}_{4} \mathrm{P}^{2+}$ leads to the following transformations in the spectra: the line with frequency 1386 $\mathrm{cm}^{-1}$ changes in form of vibration and the corresponding line with frequency $1374 \mathrm{~cm}^{-1}$ has no change of $\mathrm{C}_{2} \mathrm{~N}$ bond and participation of deformation $\delta(\mathrm{NH})$ bond vanishes. The line at $1318 \mathrm{~cm}^{-1}$ is transformed into the line with frequency $1302 \mathrm{~cm}^{-1}$ in the spectrum of $\mathrm{D}_{4} \mathrm{P}^{2+}$. The shift is due to the changing form of the mode with frequency $1302 \mathrm{~cm}^{-1}$ : the length of $\mathrm{C}_{\mathrm{a}} \mathrm{C}_{\mathrm{b}}$ bonds are decreased and the shift of the imines hydrogens is absent.

Based on the results on the geometry optimization of the molecule, the length of the $\mathrm{C}_{\mathrm{a}} \mathrm{C}_{\mathrm{b}}$ bonds for $\mathrm{H}_{4} \mathrm{P}^{2+}$ is smaller than for $\mathrm{H}_{2} \mathrm{P}$. As a result, the line in the spectrum of $\mathrm{H}_{2} \mathrm{P}$ with frequency $953 \mathrm{~cm}^{-1}$ (with participation of $\mathrm{C}_{\mathrm{a}} \mathrm{C}_{\mathrm{b}}$ bonds) will be increased to $994 \mathrm{~cm}^{-1}$ in the spectrum of $\mathrm{H}_{4} \mathrm{P}^{2+}$.

Double degenerated deformation skeletal mode with frequencies about $720 \mathrm{~cm}^{-1}$ in the FLN spectrum of $\mathrm{H}_{2} \mathrm{P}$ are splitted into two modes in the FLN spectrum of $\mathrm{H}_{4} \mathrm{P}^{2+}$ which decrease the frequencies on 12 and $28 \mathrm{~cm}^{-1}$. ${ }^{[12]}$

The length of the bonds $\mathrm{C}_{\mathrm{a}}{ }^{\prime} \mathrm{C}_{\mathrm{b}}{ }^{\prime}$ of the pyrrolic rings of $\mathrm{H}_{2} \mathrm{P}$ are more short than for the pyrroleine rings (about $0.02 \AA$ ), and as a result, the frequency $953 \mathrm{~cm}^{-1}\left(A_{1 \mathrm{~g}}\right)$ belongs to modes with participation of $\mathrm{C}_{\mathrm{a}}{ }^{\prime \prime} \mathrm{C}_{\mathrm{b}}$ " bonds, but a line with frequency $988 \mathrm{~cm}^{-1}\left(A_{1 \mathrm{~g}}\right)$ corresponds to $\mathrm{C}_{\mathrm{a}}{ }^{\prime} \mathrm{C}_{\mathrm{b}}{ }_{\mathrm{b}}$. For the diprotonated forms all rings have the same pyrrolic ring type and frequencies are totally symmetric and have the same value of $994 \mathrm{~cm}^{-1}(986$ and $972 \mathrm{~cm}^{-1}$ in the calculation results). The same value of $994 \mathrm{~cm}^{-1}$ has a mode of $B_{1}$ symmetry type which is sensitive to deuteration $\left(981 \mathrm{~cm}^{-1}\right.$ in the spectrum of $\left.\mathrm{D}_{4} \mathrm{P}^{2+}\right)$.

In comparison with the spectrum of $\mathrm{H}_{2} \mathrm{P}$, the values of the experimental and calculated frequencies for deformation modes $\delta\left(\mathrm{C}_{\mathrm{b}} \mathrm{H}\right)$ and $\delta\left(\mathrm{C}_{\mathrm{m}} \mathrm{H}\right)$ are increased in the spectrum of $\mathrm{H}_{4} \mathrm{P}^{2+}$ (see Table 1). It seems, that above mentioned effect depends on increasing force constants for angles $\mathrm{CCH}$, because the lengths of $\mathrm{C}_{\mathrm{b}} \mathrm{C}_{\mathrm{b}}$ bonds taking part in the forming of this mode are elevated and force constants are decreased.

The formation of the diprotonated form with four hydrogen atoms in the center of the porphyrin macrocycle leads to the stronger changes in vibrational frequencies. In the spectral range below $900 \mathrm{~cm}^{-1}$ in the FLN spectra of $\mathrm{H}_{4} \mathrm{P}^{2+}$ (see Figure 3), a set of new lines with frequencies 337, 479, $675,882 \mathrm{~cm}^{-1}$ is revealed. The corresponding lines are absent in the FLN spectrum and in the theoretical calculations for the in-plane modes of $\mathrm{H}_{2} \mathrm{P}$. In the FLN spectrum of $\mathrm{H}_{2} \mathrm{P}$ the lines with frequencies in the range of $430-720 \mathrm{~cm}^{-1}$ are absent, but at the same time, one of the most intensive lines (479 and $675 \mathrm{~cm}^{-1}$ ) appears in the FLN spectra of $\mathrm{H}_{4} \mathrm{P}^{2+}$ and $\mathrm{D}_{4} \mathrm{P}^{2+}$.

Table 1. Vibrational assignments of the FLN spectra of $\mathrm{H}_{2} \mathrm{P}, \mathrm{D}_{2} \mathrm{P}, \mathrm{H}_{4} \mathrm{P}^{2+}, \mathrm{D}_{4} \mathrm{P}^{2+}$ and theoretical data for $\mathrm{H}_{4} \mathrm{P}^{2+}$ and $\mathrm{D}_{4} \mathrm{P}^{2+}$.

\begin{tabular}{|c|c|c|c|c|c|c|}
\hline \multirow{2}{*}{$\frac{\mathrm{H}_{2} \mathrm{P}}{\mathrm{V}_{\exp }}$} & \multirow{2}{*}{$\frac{\mathrm{D}_{2} \mathrm{P}}{\mathrm{V}_{\exp }}$} & \multicolumn{2}{|c|}{$\mathrm{H}_{4} \mathrm{P}^{2+}$} & \multicolumn{2}{|c|}{$\mathrm{D}_{4} \mathrm{P}^{2+}$} & \multirow{2}{*}{$\begin{array}{l}\text { Maximum amplitude change for } \\
\text { natural coordinates for } \mathrm{H}_{4} \mathrm{P}^{2+}\end{array}$} \\
\hline & & $v_{\exp }$ & $V_{\text {theor }}$ & $V_{\exp }$ & $v_{\text {theor }}$ & \\
\hline \multirow[t]{4}{*}{310} & 310 & 307 & $A_{1} 298$ & 304 & 295 & $\mathrm{C}_{\mathrm{a}} \mathrm{C}_{\mathrm{m}} \mathrm{C}_{\mathrm{a}}$ \\
\hline & & 337 & $B_{2} 315$ & 334 & 314 & $\rho\left(C_{m}\right), \rho(N)$ \\
\hline & & 479 & $A_{2} 462$ & 475 & 463 & $\rho\left(C_{b}\right), \rho\left(C_{m}\right)$ \\
\hline & & 675 & $B_{2} 685$ & 672 & 684 & Fs, $\rho(\mathrm{N})$ \\
\hline 723 & 723 & 695 & $A_{1} 703$ & 690 & 705 & $\mathrm{C}_{\mathrm{a}} \mathrm{C}_{\mathrm{m}} \mathrm{C}_{\mathrm{a}}, \mathrm{C}_{\mathrm{a}} \mathrm{C}_{\mathrm{b}} \mathrm{N}$ \\
\hline 723 & 723 & 713 & $B_{2} 705$ & 711 & 702 & $\mathrm{C}_{\mathrm{a}} \mathrm{NC}_{\mathrm{a}}$ \\
\hline \multirow[t]{3}{*}{790} & 781 & 800 & $B_{1} 794$ & 787 & 770 & $\mathrm{C}_{\mathrm{a}} \mathrm{C}_{\mathrm{b}} \mathrm{C}_{\mathrm{b}}, \mathrm{C}_{\mathrm{b}} \mathrm{C}_{\mathrm{a}} \mathrm{N}$ \\
\hline & & 882 & $B_{2} 867$ & 900 & 858 & $\rho\left(\mathrm{C}_{\mathrm{m}} \mathrm{H}\right), \rho\left(\mathrm{C}_{\mathrm{b}} \mathrm{H}\right)$ \\
\hline & & 994 & $A_{1} 974$ & 952 & 940 & $\mathrm{C}_{\mathrm{a}} \mathrm{N}, \mathrm{C}_{\mathrm{b}} \mathrm{C}_{\mathrm{b}}, \mathrm{C}_{\mathrm{a}} \mathrm{NC}_{\mathrm{a}}$ \\
\hline \multirow[t]{2}{*}{976} & 868 & 994 & $B_{1} 981$ & 876 & 871 & $\mathrm{C}_{\mathrm{a}} \mathrm{N}, \mathrm{C}_{\mathrm{a}} \mathrm{C}_{\mathrm{b}} \mathrm{C}_{\mathrm{b}}, \mathrm{C}_{\mathrm{m}} \mathrm{C}_{\mathrm{a}} \mathrm{N}$ \\
\hline & & 994 & $B_{2} 986$ & 975 & 967 & $\mathrm{C}_{\mathrm{a}} \mathrm{C}_{\mathrm{b}}, \mathrm{C}_{\mathrm{a}} \mathrm{NC}_{\mathrm{a}}$ \\
\hline 1182 & 1182 & 1201 & $B_{2} 1191$ & 1192 & 1182 & $\delta\left(\mathrm{C}_{\mathrm{m}} \mathrm{H}\right), \mathrm{C}_{\mathrm{a}} \mathrm{C}_{\mathrm{b}}, \mathrm{C}_{\mathrm{a}} \mathrm{NC}_{\mathrm{a}}$ \\
\hline \multirow[t]{2}{*}{1318} & 1318 & 1318 & $A_{2} 1346$ & 1302 & 1335 & $\mathrm{C}_{\mathrm{a}} \mathrm{N}, \mathrm{C}_{\mathrm{a}} \mathrm{C}_{\mathrm{b}}, \delta\left(\mathrm{C}_{\mathrm{b}} \mathrm{H}\right), \delta\left(\mathrm{C}_{\mathrm{m}} \mathrm{H}\right), \delta(\mathrm{NH})$ \\
\hline & & 1343 & $B_{1} 1356$ & & 1349 & $\mathrm{C}_{\mathrm{a}} \mathrm{N}, \mathrm{C}_{\mathrm{a}} \mathrm{C}_{\mathrm{b}}, \delta\left(\mathrm{C}_{\mathrm{b}} \mathrm{H}\right), \delta(\mathrm{NH})$ \\
\hline \multirow[t]{2}{*}{1388} & 1388 & 1385 & $A_{2} 1363$ & 1374 & 1356 & $\delta\left(\mathrm{C}_{\mathrm{b}} \mathrm{H}\right), \delta\left(\mathrm{C}_{\mathrm{m}} \mathrm{H}\right), \delta(\mathrm{NH}), \mathrm{C}_{\mathrm{a}} \mathrm{N}$ \\
\hline & & 1385 & $A_{1} 1370$ & 1360 & 1357 & $\mathrm{C}_{\mathrm{a}} \mathrm{N}, \mathrm{C}_{\mathrm{a}} \mathrm{C}_{\mathrm{b}}$ \\
\hline \multirow[t]{2}{*}{1498} & 1498 & 1483 & $B_{2} 1466$ & 1483 & 1466 & $\mathrm{C}_{\mathrm{b}} \mathrm{C}_{\mathrm{b}}, \delta\left(\mathrm{C}_{\mathrm{b}} \mathrm{H}\right)$ \\
\hline & & 1536 & $A_{1} 1518$ & 1535 & 1518 & $\mathrm{C}_{\mathrm{a}} \mathrm{C}_{\mathrm{m}}, \mathrm{C}_{\mathrm{b}} \mathrm{C}_{\mathrm{b}}, \mathrm{C}_{\mathrm{a}} \mathrm{NC}_{\mathrm{a}}$ \\
\hline 1602 & 1594 & 1597 & $A_{2} 1572$ & 1584 & 1564 & $\mathrm{C}_{\mathrm{a}} \mathrm{C}_{\mathrm{m}}, \delta\left(\mathrm{C}_{\mathrm{m}} \mathrm{H}\right), \delta(\mathrm{NH})$ \\
\hline 1616 & 1615 & 1618 & $B_{2} 1590$ & 1602 & 1590 & $\mathrm{C}_{\mathrm{a}} \mathrm{C}_{\mathrm{m}}, \delta\left(\mathrm{C}_{\mathrm{m}} \mathrm{H}\right), \mathrm{C}_{\mathrm{a}} \mathrm{NC}_{\mathrm{a}}$ \\
\hline
\end{tabular}


In according to the results presented in Table 1 the line at $479 \mathrm{~cm}^{-1}$ belongs to the practically pure out-of-plane displacement of the $\beta$-carbon atoms of the pyrrolic rings and the carbon atoms of the methine bridges. Intensity of this line is very high, what is due to maximum out-of-plane displacement of the $\beta$-carbon atoms of the pyrrolic rings (quantum-chemical calculation). The line at $675 \mathrm{~cm}^{-1}$ corresponds to the mode with out-of-plane displacements of the nitrogen atoms of the pyrrolic rings. The line with frequency $337 \mathrm{~cm}^{-1}$ corresponds to the out-of-plane displacements of the meso-carbon atoms and the nitrogen atoms of pyrrolic rings. Out-of-plane vibration with frequency $882 \mathrm{~cm}^{-1}$ is due to out-of-plane motion of the hydrogen atoms at meso-positions and the hydrogen atoms of the pyrrolic rings together and the corresponding line is absent in the FLN spectrum of $\mathrm{H}_{2} \mathrm{P}$ with planar structure.

Based on the presented experimental data and the results of quantum-chemical calculations the main reason of activation of the out-of-plane modes in the fluorescence spectra of diprotonated forms is the distortion of the porphyrin macrocycle (saddle type of distortion). This kind of distortion should lead to realizing of out-of-plane oscillator with 3D character. In this case orientation of all electronic transition moments for $\mathrm{H}_{4} \mathrm{P}^{2+}$ would have three components $(\mathrm{X}, \mathrm{Y}$ and $\mathrm{Z}$ ) in contrary to the situation with in-plane $\mathrm{X}$ and $\mathrm{Y}$ components only of the electronic transition moments in the absorption and fluorescence spectra for the planar structure of $\mathrm{H}_{2} \mathrm{P}$. The $3 \mathrm{D}$ oscillator of the electronic (vibronic) transitions may be presented as the superposition of the plane oscillator (X and $\mathrm{Y}$ ) and out-of-plane $\mathrm{Z}$ linear oscillator with the orientation of transition moments being orthogonal to the plane (and X and Y) of the molecule. A similar 3D character would have all electronic transitions in absorption spectra of the diprotonated saddle distorted forms of $\mathrm{H}_{2} \mathrm{P}$.

It is known that the vibrational structure of the luminescence spectra of porphyrins is formed by the HerzbergTeller mechanism, i.e. by the mechanism by which vibronic transitions borrow the intensity from intense electronic transitions. Vibronic transitions with the participation of inplane vibrations are oriented in the plane of the porphyrin macrocycle and borrow the intensity from transitions in the absorption spectrum with the same orientation of transition moments. Correspondingly, out-of-plane vibrations can borrow intensity from transitions for which the orientation of the transition moments is orthogonal to the plane of the molecule (Z-components of electronic transitions).

Earlier it was discussed the possibility of the activation of out-of-plane $\mathrm{Z}$ component of the electronic transition for porphyrins. ${ }^{[13]}$ This conclusion was done on the basis of the strong effects of the conformations in the porphyrin macrocycle at interaction with solvents and the influence on the photophysical properties of distorted porphyrins. However, unambiguous evidences of the spectral manifestation of the $\mathrm{Z}$ component have not been presented. In our opinion evidence of manifestation effect of the Z-component for the saddle distorted molecules possibly is in highly-resolved fluorescence spectra only in the frequency range up to $1000 \mathrm{~cm}^{-1}$.

Recently essential out-of-plane $E_{\mathrm{g}}$ vibrations have been recorded in the fine-structure phosphorescence spectra of metallocomplexes of porphine with $\mathrm{Pd}^{\mathrm{II}}$ and $\mathrm{Pt}^{\mathrm{II}}$ ions, ${ }^{[14]}$ but the activity of these modes has another physical nature and increases with enhancing spin-orbital coupling upon changing to heavier chelated metal ions.

\section{Conclusions}

The combined theoretical and experimental investigation of the diprotonated forms of porphine allowed us to reveal a high activity of the vibronic transitions with the participation of out-of-plane vibrations in fluorescence spectra of saddle distorted above mentioned molecules. The absence of vibronic lines in the spectrum of $\mathrm{H}_{2} \mathrm{P}$ in 400-700 $\mathrm{cm}^{-1}$ range permits us to elucidate the manifestation of the out-of-plane modes in the FLN spectra of $\mathrm{H}_{4} \mathrm{P}^{2+}$ and $\mathrm{D}_{4} \mathrm{P}^{2+}$, because interference between in- and out-of-plane modes does not take place. High activity of the out-of-plane modes in the FLN spectra of the diprotonated forms was interpreted as a result of vibronic borrowing with participation of $Z$-component for 3D character electronic transitions for the distorted structure of the diprotonated forms.

Acknowledgements. This work was supported by the Foundation for Fundamental Research of Republic of Belarus (project Ch10R-001) and a FP-7 grant from the EC for Research, Technological Development and Demonstration Activities, "Dendrimers for Photonic Devices" IRSESPEOPLE-2009-247260-DphotoD, under the "International Research Staff Exchange Scheme". W. Maes also thanks FWO (Fund for Scientific Research - Flanders), KU Leuven, Hasselt University and the Ministerie voor Wetenschapsbeleid for continuing financial support.

\section{References}

1. Personov R.I., Al'shits E.I., Bykovskaya L.A. Opt. Commun. 1973, 7, 169-173.

2. Gradyushko A.T., Knyukshto V.N., Solovyov K.N., Tsvirko M.P. J. Appl. Spectrosc. 1975, 23, 444-451.

3. Tsvirko M.P., Solovyov K.N., Knyukshto V.N., Gradyushko A.T. J. Appl. Spectrosc., 1975, 23, 644-647.

4. Stone A., Fleisher E.B. J. Am. Chem. Soc. 1968, 90, 2735-2748.

5. Cheng B., Murno O.Q., Marques H.M., Sheidt W.R. J. Am. Chem. Soc. 1997, 119, 10732-10742.

6. Solovyov K.N., Stanishevskii I.V., Starukhin A.S., Shul'ga A.M. Izv. Akad. Nauk SSSR, Ser. Fiz. 1983, 47, 1399-1404 (in Russ.).

7. Arabei S.M., Solovyov K.N., Pavich T.A. J. Appl. Spectrosc. 2002, 69, 695-701.

8. Singh A., Johnson L.W. Spectrochim. Acta, Part A 2006, 64, 761-770.

9. Saburo N., Noriaki F. Tetrahedron Lett. 2002, 43, 1057-1058.

9. Starukhin A.S., Shul'ga A.M. Opt. Spectrosc. 2005, 98, 780-785.

10. Laikov D.N. Chem. Phys. Lett. 1997, 281, 151-156.

11. Solov'ev K.N., Gladkov L.L., Starukhin A.S., Shkirman S.F. In: Spektroskopiyay Porfirinov: Kolebatel'nye Sostoyaniya [Spectroscopy of Porphyrins: Vibrational States]. Minsk: Nauka i Tekhnika. 1985, pp. 239-252. (in Russ.)

12. Sazanovich I.V., Galievsky V.A., van Hoek A., Schaafsma T.J., Malinovskii V.L., Holten D., Chirvony V.S. J. Phys. Chem. B 2001, 105, 7818-7829.

13. Gladkova O.L., Starukhin A.S., Kruk M.M. Opt. Spectrosc. 2011, 110, 234-241. 